\title{
Syneresis and rheological behaviors of set yogurt containing green tea and green coffee powders
}

\author{
Özge Dönmez, Burçe Ataç Mogol, and Vural Gökmen ${ }^{1}$ \\ Food Quality and Safety (FoQuS) Research Group, Department of Food Engineering, Hacettepe University, 06800 Beytepe Campus, \\ Ankara, Turkey
}

\begin{abstract}
This study aimed to investigate the effect of added green coffee powder (GCP) and green tea powder (GTP) on syneresis behavior and consistency of set yogurts. Adding GCP (1 or 2\%) decreased syneresis rate. The effect of GTP on the syneresis rate was concentration dependent. In comparison to the control, GTP decreased syneresis rate when it was added at $0.02 \%$, but it caused an increase when added at $2 \%$. No significant difference was observed in the syneresis rates when GTP was added at 1 and $0.01 \%$, until 14 and 7 d of storage, respectively. The Herschel-Bulkley model parameters indicated that the consistency of control was considerably lower than that of GCP yogurts during $14 \mathrm{~d}$, whereas it was higher at the end of storage. The GTP yogurt results showed that the consistency coefficients of GTP yogurts were different from those of control samples until $14 \mathrm{~d}$ of storage. In conclusion, GTP and GCP behaved differently in acidified gel networks of set yogurt, modifying its rheological behavior, as they have different profiles and concentrations of polyphenols.
\end{abstract}

Key words: set yogurt, green tea, green coffee, proteinpolyphenol interaction, syneresis rate

\section{INTRODUCTION}

Yogurt is a widely consumed dairy product because of its positive health effects (Loveday et al., 2013). Casein plays an important role in the formation of gel matrix via aggregation of casein micelles as the $\mathrm{pH}$ approaches 4.6 as a result of lactic acid production during fermentation (McCann et al., 2011; Cui et al., 2014). Set yogurts, usually fermented "in pack," have firmer structure than stirred yogurts because there is no mechanical effect such as shearing (Loveday et al., 2013).

Rheology builds a bridge between structural microscopic aspects and continuous macroscopic parameters

Received April 2, 2016.

Accepted August 3, 2016.

${ }^{1}$ Corresponding author: vgokmen@hacettepe.edu.tr
(Gabriele et al., 2001). The microstructure and the rheological properties of set yogurts are considerably critical to product quality and shelf life (Nguyen et al., 2015). Syneresis, serum release from the gel matrix, is regarded as a technological defect in set yogurts. The addition of milk-based compounds, use of some polysaccharides and protein hydrocolloids, changing the concentration of starter culture, use of stabilizers such as xanthan gum and pectin, and changing the process conditions have been reported to enhance the technological properties of yogurt (Jaros et al., 2002; Amatayakul et al., 2006; Riener et al., 2010; Delikanli and Ozcan, 2014; Puvanenthiran et al., 2014; Nguyen et al., 2015).

Polyphenols, secondary plant metabolites, have the ability to interact with proteins, resulting in the formation of protein-polyphenol complex (Woof and Pierce, 1968; von Staszewski et al., 2011; Jakobek, 2015). Interactions between polyphenols and proteins are mostly based on multiple weak interactions, mainly hydrophobic, van der Waals, hydrogen bridge-binding, and ionic interactions formed between AA side chains and polyphenol aromatic rings, indicating that the association of polyphenols with proteins is principally a surface phenomenon. Hasni et al. (2011) examined that the interactions between tea polyphenols and $\alpha-\mathrm{CN}$ and $\beta$-CN using Fourier transform infrared, UV-visible fluorescence spectroscopic methods and found that the binding mechanisms were both hydrophobic and hydrophilic interactions. The formation or precipitation of protein-polyphenol complex was modeled by many researchers (Siebert et al., 1996; Charlton et al., 2002; Jobstl et al., 2004; Lin et al., 2004; Poncet-Legrand et al., 2006; Richard et al., 2006).

Even when compared with other polyphenol-rich, plant-based foods, green tea and green coffee contain high levels of polyphenols. Chlorogenic acid represents 4.1 to $11.3 \mathrm{~g} / 100 \mathrm{~g}$ of the green coffee seeds, whereas catechins constitute 30 to $42 \%$ of green tea extract solids (Graham, 1992; Farah, 2012). This study aimed to investigate the effect of protein-polyphenol interaction on the syneresis of set type yogurts by using green coffee and green tea powders. The effects of different amounts 
of green tea or green coffee powders were determined on syneresis rate and consistency of set yogurts using a centrifugal acceleration test and rheological measurement, respectively, during 3 wk of storage at $4^{\circ} \mathrm{C}$.

\section{MATERIALS AND METHODS}

\section{Chemicals and Consumables}

Pasteurized $\left(85^{\circ} \mathrm{C}\right.$ and $\left.5 \mathrm{~min}\right)$ and homogenized milk (3\% protein, $3 \%$ fat), green coffee beans (Coffea canephora var. 'Robusta'), and green tea leaves were supplied from a local market in Turkey. A freeze-dried lactic acid culture YF-L812, containing a mixture of Streptococcus thermophilus and Lactobacillus bulgaricus, was obtained from Chr. Hansen (Victoria, Australia).

Sodium carbonate, sodium hydroxide, potassium sulfate, boric acid, hydrochloric acid (37\%), and sulfuric acid (95\%) were purchased from Merck (Darmstadt, Germany). Ethanol (96\%) and Folin-Ciocalteu Reagent $(2 N)$ were obtained from Sigma-Aldrich (Steinheim, Germany). Cupric sulfate pentahydrate was purchased from Fluka Chemie AG (Buchs, Switzerland). Gallic acid (98\%) was from Acros (Geel, Belgium).

\section{Preparation of Green Tea and Green Coffee Powders}

Green tea brew was prepared by the extraction of coarsely ground green tea leaves. Thirty grams of green tea was extracted into $1 \mathrm{~L}$ of boiling water by keeping it at $90^{\circ} \mathrm{C}$ in a water bath for $30 \mathrm{~min}$. Green tea leaves were removed by using a filter paper (Macherey-Nagel $751 / 60$ ). Then, the green tea extract was immediately lyophilized to obtain green tea powder (GTP). The freeze-drying was performed for $48 \mathrm{~h}$ (Christ Alpha 1-2 $\mathrm{LD}+$, Osterode, Germany) operated at $0.1 \mathrm{~Pa}$ and ice condenser temperature of $76^{\circ} \mathrm{C}$.

Six grams of finely ground green coffee was weighed into an espresso cap and the first $25 \mathrm{~mL}$ of extract was collected from the espresso machine (Ecov 311.BK Icona Vintage, DeLonghi, Treviso, Italy). The procedure was repeated until enough extract was obtained. The combined green coffee extract was lyophilized to obtain green coffee powder (GCP). Both GCP and GTP were stored at $-18^{\circ} \mathrm{C}$ until the yogurts would be prepared.

The total phenolic content of the GTP and GCP was determined according to the Folin-Ciocalteu colorimetric method (Yilmaz and Gokmen, 2013). One hundred milligrams of powders was mixed with $10 \mathrm{~mL}$ of ethanolwater $(50: 50, \mathrm{vol} / \mathrm{vol})$ in a test tube. Then, the samples were vortexed for $1 \mathrm{~min}$ and centrifuged at 5,500 $\times \mathrm{g}$ for $3 \mathrm{~min}$ at room temperature. Then, $0.2 \mathrm{~mL}$ of the supernatant was transferred to another test tube and mixed with $0.8 \mathrm{~mL}$ of $0.2 \mathrm{~N}$ Folin-Ciocalteu reagent and $0.8 \mathrm{~mL}$ of $20 \%$ aqueous $\mathrm{Na}_{2} \mathrm{CO}_{3}$, consecutively. The reaction mixture was subsequently incubated at $25^{\circ} \mathrm{C}$ for $2 \mathrm{~h}$. Then, the absorbance of the samples was measured at $765 \mathrm{~nm}$ using a Shimadzu model 2100 variable wavelength UV-Vis spectrophotometer (Shimadzu, Kyoto, Japan). Standard calibration curve was prepared by using gallic acid between the ranges of 0 to $100 \mathrm{mg} / \mathrm{L}$. Three independent measurements were performed and the total phenolic content was expressed as milligrams of gallic acid equivalents (GAE) per gram of sample.

\section{Preparation of Yogurts}

Pasteurized milk was heated to $42^{\circ} \mathrm{C}$ and then rapidly inoculated with direct vat set starter culture (3 $\mathrm{g} / 100 \mathrm{~mL}$ ). As soon as the inoculation was performed, $\operatorname{GCP}(0,1$, and $2 \%)$ or $\operatorname{GTP}(0,0.01,0.02,1$, and $2 \%)$ was immediately added to the milk. The samples were incubated at $42^{\circ} \mathrm{C}$ until the $\mathrm{pH}$ reached to 4.6 in $3 \mathrm{~h}$ and then at $4^{\circ} \mathrm{C}$ for $18 \mathrm{~h}$. The GCP-added yogurt (GCP yogurt) and GTP-added yogurt (GTP yogurt) samples were stored at $4^{\circ} \mathrm{C}$ for $21 \mathrm{~d}$ and the analyses were performed on d 1, 7, 14, and 21 of storage. All yogurts were prepared in duplicate with one lot of milk.

The $\mathrm{pH}$ values (PHM210 MeterLab, Lyon France) and the color information in CIE $\mathrm{L}^{*} \mathrm{a}^{*} \mathrm{~b}^{*}$ space (Minolta colorimeter CM3600d, Tokyo, Japan) were monitored to evaluate quality characteristics of yogurts during cold storage. The $\mathrm{pH}$ and color measurement were performed at room temperature. The color values of the control sample were taken as the reference to calculate color differences $(\boldsymbol{\Delta E})$ of GCP and GTP yogurts, by using Equation [1]. In CIE L*a*b* space, $\mathrm{L}^{*}$ represents luminance or lightness. The $\mathrm{a}^{*}$ and $\mathrm{b}^{*}$ chromatic components represent colors from green to red, and blue to yellow, respectively.

$$
\Delta \mathrm{E}=\sqrt{\left(\mathrm{L}_{1}-\mathrm{L}_{2}\right)^{2}+\left(\mathrm{a}_{1}-\mathrm{a}_{2}\right)^{2}+\left(\mathrm{b}_{1}-\mathrm{b}_{2}\right)^{2}} .
$$

\section{Determination of the Syneresis Rate}

The syneresis rates of yogurts were determined by a centrifugal acceleration test. Five grams of yogurt sample was placed in a test tube and centrifuged at $1,200 \times g$ for $0,3,6,9,12$, and 15 min at room temperature. At each time interval, the volume of the serum separated from the samples was measured to estimate the initial rate of syneresis, which was expressed as milliliters of serum released per gram of sample per unit of time. The average of the 5 times (except 0 ) tested was reported to evaluate the syneresis rate for that day. 


\section{Rheological Analysis}

Rheological property of yogurts was specified with a Brookfield RVDV-II+P (Middleboro, MA) under controlled temperature by using a Cone CP-40. The yogurt samples were gently stirred 30 times for homogenization. Then, $0.5 \mathrm{~g}$ of yogurt sample was placed into the cap and the temperature of the water bath was set to $20^{\circ} \mathrm{C}$ to prevent the temperature fluctuations during measurements. The samples were exposed to high shear rate $\left(500 \mathrm{~s}^{-1}\right)$ for $60 \mathrm{~s}$ to obtain a better homogenization and make same starting conditions for all yogurts. Following this procedure, samples were maintained for $300 \mathrm{~s}$ without shear rate to rebuild structure of yogurt samples as described by Purwandari et al. (2007). The flow curve was generated by measuring the shear stress as a function of shear rates from 0.1 to $400 \mathrm{~s}^{-1}$ by using DVLoader software (Brookfield Ametek, Middleborough, MA). The Herschel-Bulkley model $\left(\tau=\tau^{o}+K \gamma^{n}\right)$, where $\tau$ is the shear stress of the material, $\tau^{o}$ is the apparent yield stress, $K$ is the consistency coefficient, $\gamma$ is the shear rate, and $n$ is the flow behavior index of the material, was fitted to measurement results. The consistency coefficients of GCP and GTP yogurts were normalized to use the control as base of $100 \mathrm{~Pa} \cdot \mathrm{s}$.

\section{Statistical Analysis}

After preliminary experiment, those concentrations were chosen due to the sensorial acceptance. The Tukey post-hoc test was employed to determine the significance of the difference within treatments for each analysis. A total of 2 replicates were performed and the mean values were calculated. Values were considered significantly different when $P<0.05$. The results were reported as mean \pm standard deviation. All statistical analyses were performed by using the SPSS 13.0 statistical program package (SPSS Inc., Chicago, IL).

\section{RESULTS AND DISCUSSION}

\section{Syneresis Rate}

Serum release, known as syneresis, is considered as one of the most important parameters indicating the quality of yogurt during storage. Figure 1 shows the changes in the syneresis rates of yogurts added with different amounts of GCP and GTP. Here, the syneresis rate was expressed as milliliters of serum phase released per gram of sample per unit of time. Addition of GCP was found to decrease the syneresis rate of yogurts compared with control during storage (Figure 1a). The decrease in the syneresis rate was proportional to the increase in coffee concentration, so that the serum separation was significantly restricted when $2 \%$ GCP was added $(P<0.05)$. In the case of GTP yogurts, adding $2 \%$ GTP concentration resulted in increase in the syneresis rate, unlike GCP yogurts (Figure 1b). Sengul et al. (2012) also reported that increased concentrations of sour cherry as the polyphenol source in yogurts led to an increase in the serum separation. The syneresis rate was found to be significantly lower for $0.02 \%$ GTP yogurts compared with control $(P<0.05)$, whereas it was higher for $2 \%$ GTP yogurts. Moreover, storage time showed no statistically significant effect on the syneresis rate of the GCP and GTP yogurt samples $(P>0.05)$.

Considering the addition of increased amounts of GTP and GCP, which means increased total phenolic content, one would expect retention of more serum phase in the yogurt structure. However, having different total phenolic content of GCP (35 mg of GAE/g of sample) and GTP (61 mg of GAE/g of sample) added yogurts showed different behaviors depending on their concentrations, which could be explained by the protein-polyphenol interaction model proposed by
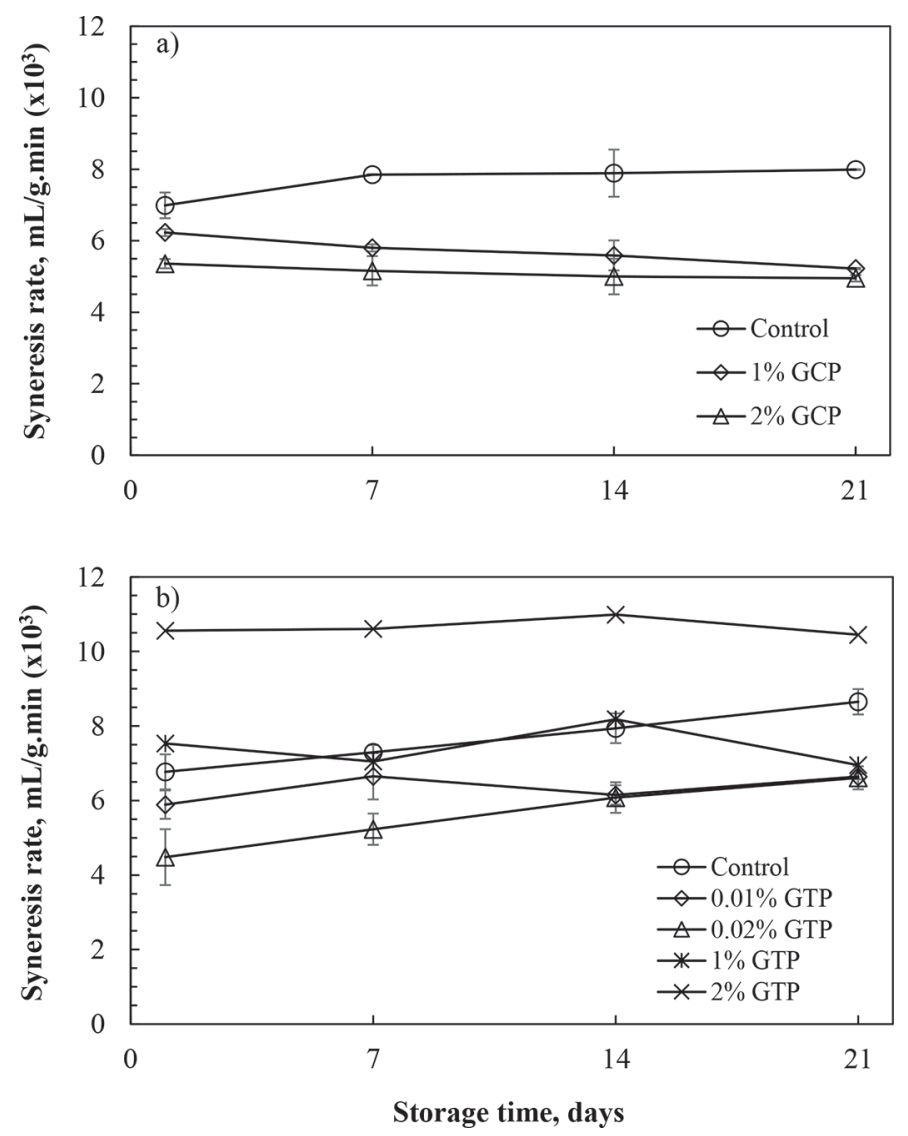

Figure 1. Changes in the syneresis rates for yogurts added with (a) green coffee powder (GCP), and (b) green tea powder (GTP) during cold storage. The error bars represent SD of the mean. 
Siebert et al. (1996; Figure 2). According to this model, our goal was to fix the number of polyphenol binding sites of protein molecules and the number of polyphenols, which leads to create new cages that could have a role in limiting the serum release from the gel network (Figure 2a). The interaction of polyphenols with proteins in $2 \%$ GCP yogurts was found to be well enough to strengthen the gel structure of yogurt, which led to decreased syneresis rate. On the other hand, the reason of the increased syneresis rates, observed in $2 \%$ GTP yogurts, could be explained with the model shown in Figure 2c. Excess green-tea polyphenol concentrations increased the number of cages, but decreased the volume of the individual cage, leading to a reduction of the time of serum trap in the gel matrix. The syneresis of GTP yogurts at lower concentrations (0.02 and 0.01\%) was similar to the 1 and $2 \%$ GCP yogurts. This is the result of different amount and profile of polyphenols present in GTP and GCP.

When increasing the number of particle-particle junctions in the gel structure, the network then tends to shrink, thereby dismissing interstitial liquid (Walstra et al., 2006). Undoubtedly, the tendency to exhibit

\section{A $[$ phenol $]=[$ protein $]$}

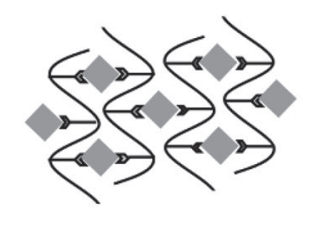

B $[$ phenol] $<$ [protein]

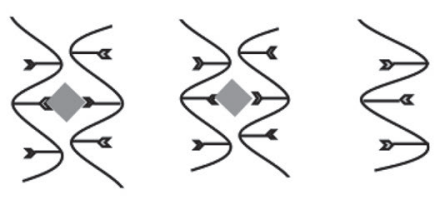

C $[$ phenol] $>$ [protein]

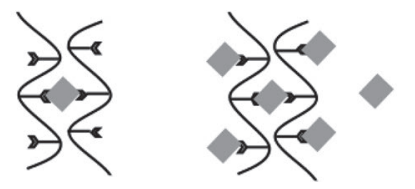

Figure 2. Proposed model to explain the gel structure stability of yogurts for different ratios of [protein] and [polyphenol]. Reprinted (adapted) with permission from Siebert et al., 1996. Copyright 1996 American Chemical Society. syneresis also depends on the changing in $\mathrm{pH}$, which affects the gel structure, which is a casein micelle network containing heat-denatured whey proteins bound to the surface of the casein micelles (Delikanli and Ozcan, 2014). Continuing to grow the lactic acid bacteria and also to produce lactic acid through the storage is responsible for the reduction in the $\mathrm{pH}$ (Lucey, 2004). The change in $\mathrm{pH}$ values of yogurts during storage is given in Table 1 . The $\mathrm{pH}$ values of yogurts differed between 4.58 and 4.89 . The results showed no statistically significant difference between control and GCP yogurts during first $7 \mathrm{~d}$ of storage $(P>0.05)$. However, the $\mathrm{pH}$ value of control was different from GTP and GCP yogurts after d 7 and 14 , respectively $(P<0.05)$. Compared with control yogurts, $1 \%$ and $2 \%$ GCP yogurts showed significantly higher $\mathrm{pH}$ values between 14 and $21 \mathrm{~d}$. The results of syneresis rate in this time period could also be affected by $\mathrm{pH}$ in a similar manner. This phenomenon might be due to rearrangement of the forces keeping the structural elements of a micelle together. Acidification causes several changes such as dissolving the calcium and inorganic phosphate gradually and decreasing the net negative electric charge of the casein micelles, including that of the hairy layer. As the layer collapses, the casein itself becomes insoluble near its isoelectric $\mathrm{pH}$ (about 4.6). Altogether, this results in aggregation. Even a small decrease of the $\mathrm{pH}$ leads to a decreased charge, which weakens colloidal stability (Walstra et al., 2006). It could enhance serum releasing from the gel matrix. Moreover, Lucey (2002) explained that postacidification is one of the factors that can increase the production of whey in yogurts.

\section{Rheological Behavior}

Flow characteristics of yogurt attempted to be explained by using different rheological models such as the Power Law model and Herschel-Bulkley model (Fangary et al., 1999; Mullineux and Simmons, 2008). Figure 3 shows the examples of the relationship between the shear stress $(\tau)$ and shear rate $(\gamma)$, explained by the Herschel-Bulkley model, for GCP yogurts $(0,1$, and $2 \%$ ) and GTP yogurts $(0,0.02$, and $2 \%)$. The model parameters, namely consistency coefficient, flow behavior index, and yield stress, were calculated from the model. The coefficient of determination $\left(\mathrm{R}^{2}\right)>0.994$ indicated that the Herschel-Bulkley model successfully described the rheological behavior of set yogurt samples.

The model parameters indicated that the consistency coefficient of control yogurt increased significantly $(P$ $<0.05)$ during $21 \mathrm{~d}$ of storage, but no significant differences $(P>0.05)$ were found between 1 and $2 \%$ GCP yogurts up to $14 \mathrm{~d}$ of storage (Figure 4 ). On the other hand, the consistency of control was considerably lower 
Table 1. Changes in $\mathrm{pH}\left(\right.$ at $\left.20^{\circ} \mathrm{C}\right)$ of yogurt samples during cold storage ${ }^{1}$

\begin{tabular}{lcccc}
\hline & \multicolumn{4}{c}{$\mathrm{pH}$} \\
\cline { 2 - 5 } Item & Day 1 & Day 7 & Day 14 & Day 21 \\
\cline { 2 - 5 } Control & $4.66 \pm 0.06^{\mathrm{a}, \mathrm{A}}$ & $4.66 \pm 0.01^{\mathrm{a}, \mathrm{A}}$ & $4.66 \pm 0.01^{\mathrm{a}, \mathrm{C}}$ & $4.65 \pm 0.00^{\mathrm{a}, \mathrm{B}}$ \\
$1 \%$ GCP & $4.71 \pm 0.00^{\mathrm{a}, \mathrm{A}}$ & $4.71 \pm 0.03^{\mathrm{a}, \mathrm{A}}$ & $4.71 \pm 0.01^{\mathrm{a}, \mathrm{B}}$ & $4.74 \pm 0.04^{\mathrm{a}, \mathrm{A}}$ \\
$2 \%$ GCP & $4.69 \pm 0.00^{\mathrm{b}, \mathrm{A}}$ & $4.72 \pm 0.04^{\mathrm{ab}, \mathrm{A}}$ & $4.75 \pm 0.01^{\mathrm{b}, \mathrm{A}}$ & $4.76 \pm 0.00^{\mathrm{a}, \mathrm{A}}$ \\
& & & \\
Control & $4.89 \pm 0.01^{\mathrm{a}, \mathrm{A}}$ & $4.67 \pm 0.03^{\mathrm{b}, \mathrm{C}}$ & $4.58 \pm 0.02^{\mathrm{b}, \mathrm{C}}$ & $4.59 \pm 0.01^{\mathrm{b}, \mathrm{B}}$ \\
$0.01 \%$ GTP & $4.88 \pm 0.04^{\mathrm{a}, \mathrm{A}}$ & $4.71 \pm 0.04^{\mathrm{b}, \mathrm{BC}}$ & $4.81 \pm 0.00^{\mathrm{a}, \mathrm{A}}$ & $4.80 \pm 0.03^{\mathrm{a}, \mathrm{A}}$ \\
$0.02 \%$ GTP & $4.79 \pm 0.01^{\mathrm{a}, \mathrm{B}}$ & $4.72 \pm 0.04^{\mathrm{a}, \mathrm{BC}}$ & $4.72 \pm 0.01^{\mathrm{a}, \mathrm{B}}$ & $4.75 \pm 0.04^{\mathrm{a}, \mathrm{A}}$ \\
$1 \%$ GTP & $4.82 \pm 0.04^{\mathrm{a}, \mathrm{AB}}$ & $4.80 \pm 0.01^{\mathrm{ab}, \mathrm{A}}$ & $4.74 \pm 0.01^{\mathrm{b}, \mathrm{B}}$ & $4.73 \pm 0.03^{\mathrm{b}, \mathrm{A}}$ \\
$2 \%$ GTP & $4.79 \pm 0.04^{\mathrm{a}, \mathrm{B}}$ & $4.76 \pm 0.03^{\mathrm{a}, \mathrm{AB}}$ & $4.73 \pm 0.01^{\mathrm{a}, \mathrm{B}}$ & $4.71 \pm 0.06^{\mathrm{a}, \mathrm{A}}$ \\
\hline
\end{tabular}

$\overline{\mathrm{a}, \mathrm{b}}$ Superscript lowercase letters in each row indicate statistically significant difference $(P<0.05)$ during storage.

${ }^{\mathrm{A}-\mathrm{C}}$ Superscript uppercase letters indicate statistically significant difference $(P<0.05)$ between yogurt samples in each column within the type of the product.

${ }^{1}$ Data are expressed as mean $\pm \mathrm{SD}(\mathrm{n}=2)$. GTP $=$ green tea powder, GCP $=$ green coffee powder.

than GCP yogurts during $14 \mathrm{~d}$, whereas it was found to be higher at the end of storage. The GTP yogurt results showed that the consistency coefficients of GTP yogurts were significantly different from the control samples until $14 \mathrm{~d}$ of storage $(P<0.05)$. Lower concen-
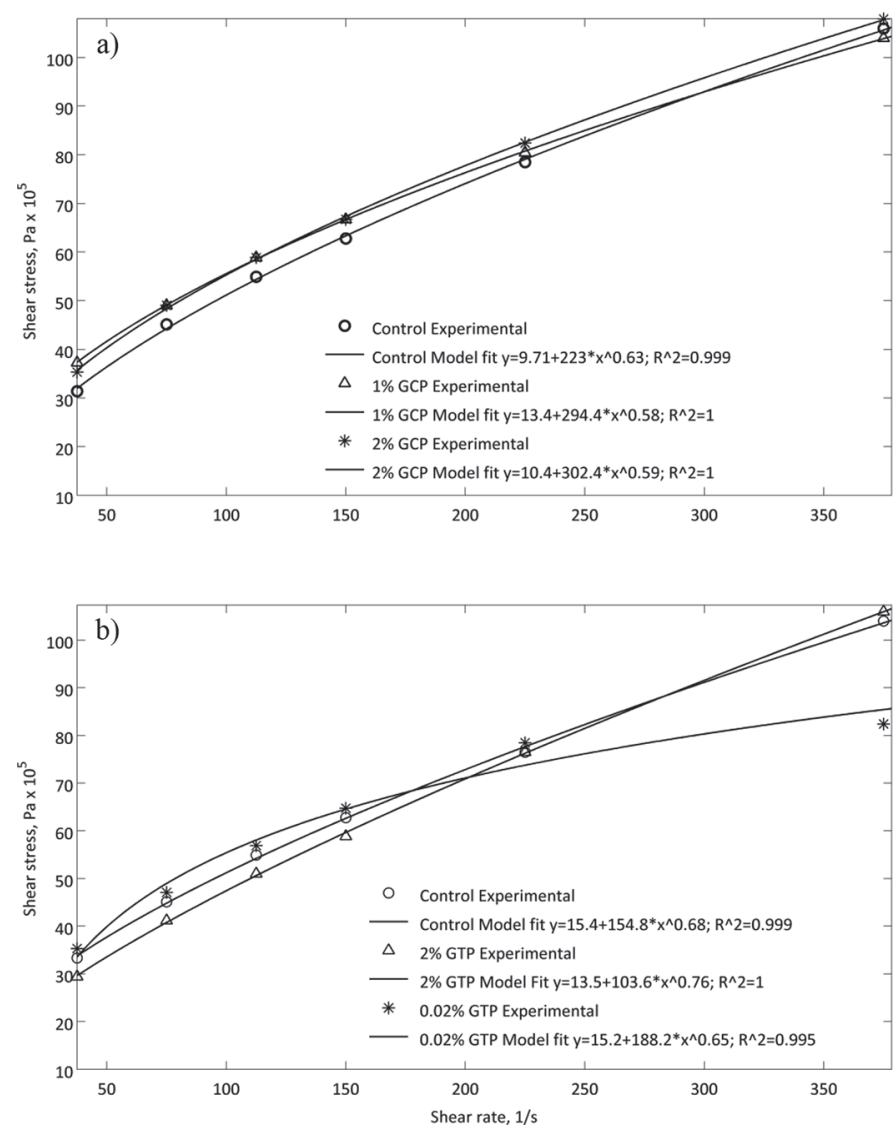

Figure 3. Examples of the plots of the Herschel-Bulkley model fits for yogurts at $20^{\circ} \mathrm{C}$ added with (a) green coffee powder (GCP), and (b) green tea powder (GTP). trations (i.e., 0.01 and $0.02 \%$ ) caused increased consistency compared with control during storage $(P<0.05)$. However, lower consistency coefficients were obtained in GTP yogurts when the GTP concentration increased to 1 or $2 \%$. Highest and lowest consistencies were obtained in 0.02 and $2 \%$ GTP yogurts, respectively. Increasing the viscosity of yogurt samples can be explained by postacidification. The lactic acid bacteria continue to produce lactic acid over shelf life, a phenomenon known as postacidification. Postacidification causes several adverse effects on yogurt quality such as strong acid taste and increase of whey separation (Han et al., 2012). Xu et al. (2015) also reported that when yogurt samples were fermented by different acidifying strains of Lactobacillus delbrueckii ssp. bulgaricus, both weak postacidification and higher viscosity were observed in yogurt samples during storage. The effect of changing in $\mathrm{pH}$ to the yogurt structure has already been discussed above. As a result, strengthening of protein-protein complexes, forming yogurt structure, via protein-polyphenol interaction and the weak postacidification may have been responsible for the increase in consistency. Meanwhile, the range of mean flow behavior index was found to be between 0.78 and 0.58 , and the apparent viscosity decreased with increasing shear rate (the data were not shown). These findings referred the shear-thinning phenomenon, which also showed the pseudoplastic behavior for each sample at all concentrations (Fischer et al., 2009; Espirito-Santo et al., 2013). Figure 5a demonstrates that the flow behavior index of GCP yogurts and control, ranging between 0.58 and 0.65 , did not significantly changed during $21 \mathrm{~d}$ of storage $(P>0.05)$. The same trend was observed in GTP yogurts in low concentrations (0.01 and $0.02 \%)$. No significant difference was observed for the parameter $\mathrm{n}$ for these yogurt samples, indicating that they all had similar degrees of shear thinning. However, the flow behavior index of 
1 and $2 \%$ GTP yogurts was significantly higher $(P<$ 0.05 ) than control and 0.01 and $0.02 \%$ GTP yogurts the first day of storage, whereas it decreased until 14 $\mathrm{d}$ of the storage (Figure 5b). After $14 \mathrm{~d}$, flow behavior indices of all samples remained constant until the end of the storage. The set yogurt system is a dispersion system consisting of many particles and causes the formation of yield stress, which is defined as the required initial force to initiate the yogurt to flow (Cui et al., 2014). The yield stress of the samples changed between $8.1 \times 10^{5}$ and $23.1 \times 10^{5} \mathrm{~Pa}$. No significant difference was observed for the yield stress for the yogurt samples during storage (data not shown).

\section{Changes in Color During Storage}

Color is one of the most important visual attributes in dairy products, and color differences affect storage, shelf life, and color deterioration of yogurt (Coggins et al., 2010). The total $\Delta \mathrm{E}$ is important, so that all differences encountered between $\mathrm{L}^{*}, \mathrm{a}^{*}, \mathrm{~b}^{*}$ color values of the samples and control are taken into account.
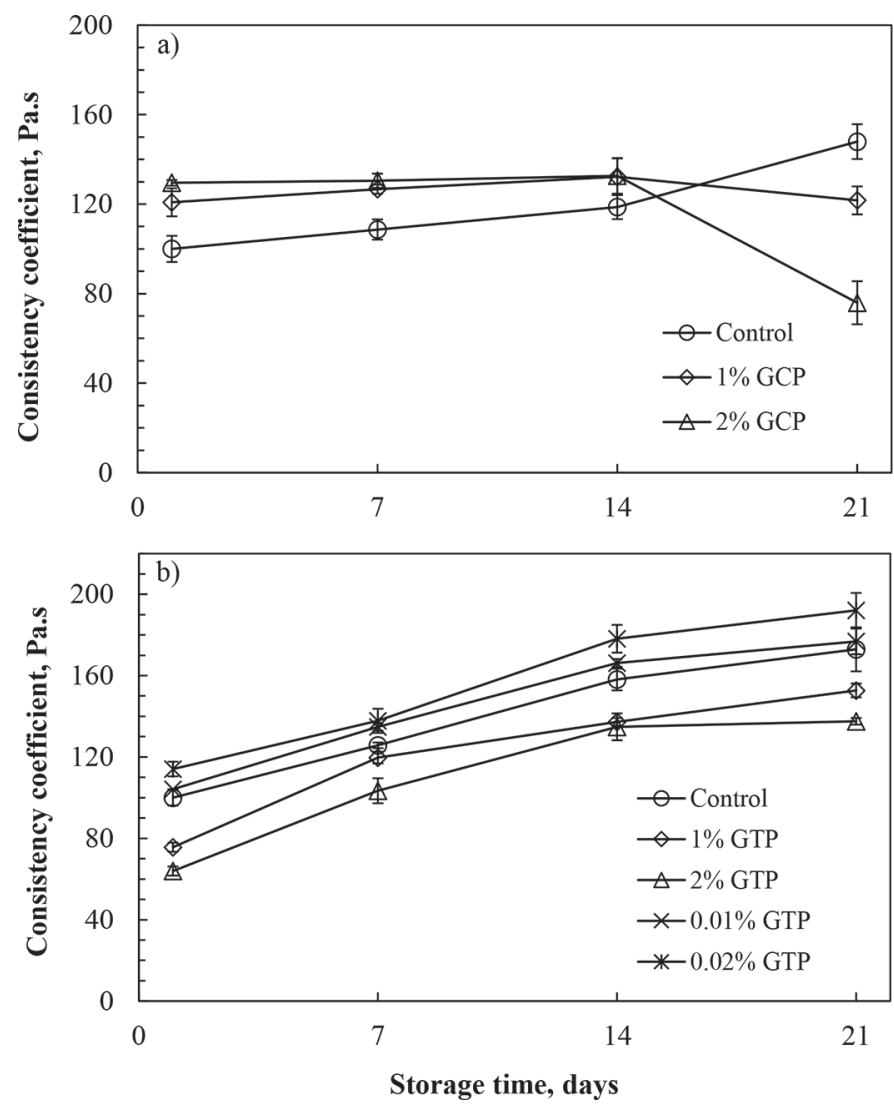

Figure 4. Changes in the consistency coefficients $\left(\right.$ at $20^{\circ} \mathrm{C}$ ) calculated from the Herschel-Bulkley model fit equations for yogurts added with (a) green coffee powder (GCP), and (b) green tea powder (GTP) during cold storage. The error bars represent SD of the mean.
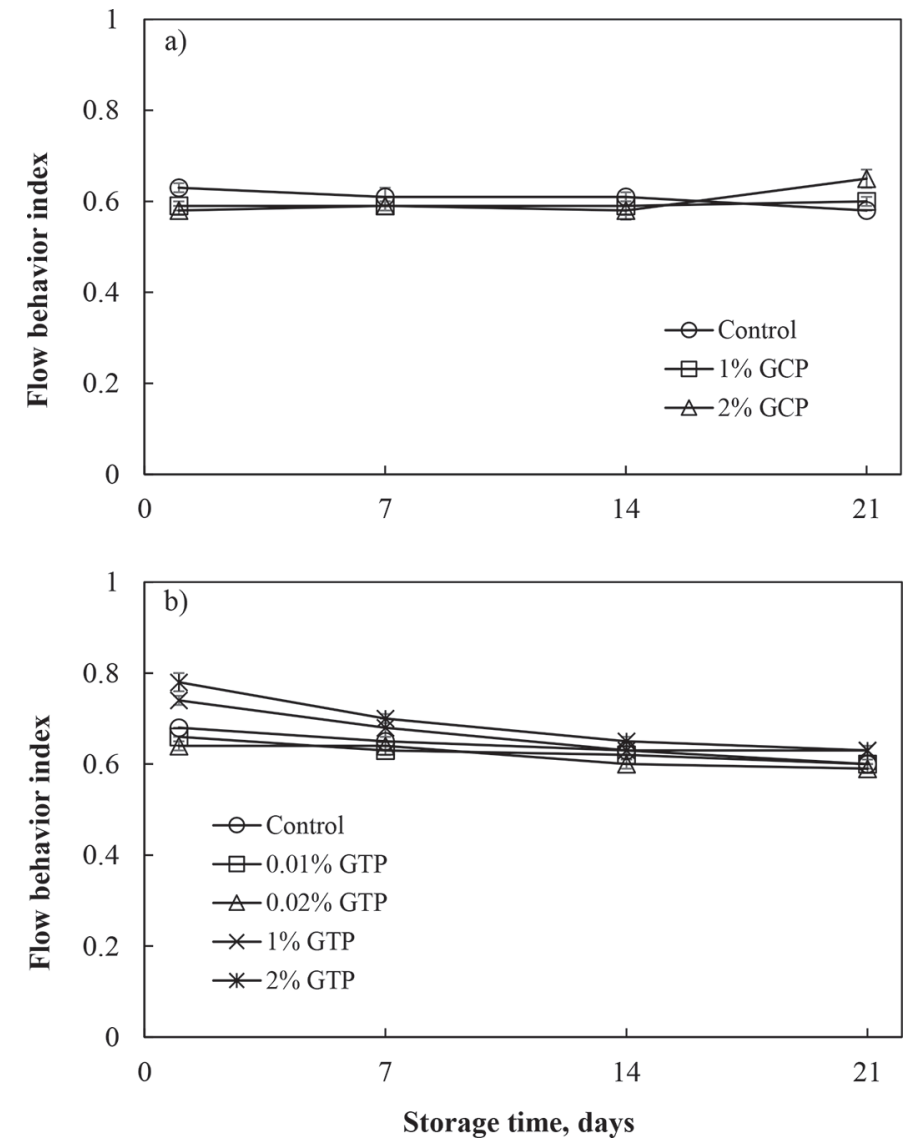

Figure 5. Changes in the behavior indices (at $20^{\circ} \mathrm{C}$ ) calculated from the Herschel-Bulkley model fit equations for yogurts added with (a) green coffee powder (GCP), and (b) green tea powder (GTP) during cold storage. The error bars represent $\mathrm{SD}$ of the mean.

The $\Delta \mathrm{E}$ values $(<1.0)$ indicated no difference between control sample and low concentrations of GTP yogurts (0.01 and 0.02\%; Mokrzycki and Tatol, 2011). The $\Delta \mathrm{E}$ values of GTP yogurts and GCP yogurts (1 and 2\%) GCP yogurts (1 and $2 \%$ ) were calculated as $7.73,12.4$, and $3.07,6.29$, respectively. This result implied that an increase in the concentration of GCP or GTP caused an increase in the $\Delta \mathrm{E}$ values. Additionally, no significant differences were found in color values $\left(\mathrm{L}^{*}, \mathrm{a}^{*}, \mathrm{~b}^{*}\right)$ of all samples throughout $21 \mathrm{~d}$ of storage $(P>0.05$; data were not shown).

\section{CONCLUSIONS}

The modification of technological properties of dairy products such as yogurt has gained considerable interest for the development of new products. The results indicated that green tea and green coffee powders, which are rich in polyphenols, could significantly modify the syneresis and rheological behaviors of set yogurts. These powders affected the gel matrix of yogurts 
differently in a concentration-dependent manner. It is thought that the differences in the polyphenol profiles of green tea and green coffee played a certain role on the observed differences of the yogurts added with their powders. Overall, polyphenols present in green coffee and green tea could interact with casein micelles in yogurt. Consequently, this protein-polyphenol interaction promoted the strength of the casein network and stabilized yogurt structure by increasing the consistency and reducing the syneresis rate at certain concentrations. Incorporation of GCP and GTP at a ratio of 2.0 and $0.02 \%$, respectively, is recommended to improve the gel structure of set yogurts. The powders obtained from green coffee and green tea are promising ingredients from a technological point of view. In addition, these natural ingredients draw attention due to their healthpromoting properties, which make them easily adopted by consumers.

\section{REFERENCES}

Amatayakul, T., F. Sherkat, and N. P. Shah. 2006. Syneresis in set yogurt as affected by EPS starter cultures and levels of solids. Int. J. Dairy Technol. 59:216-221.

Charlton, A. J., N. J. Baxter, M. L. Khan, A. J. G. Moir, E. Haslam, A. P. Davies, and M. P. Williamson. 2002. Polyphenol/peptide binding and precipitation. J. Agric. Food Chem. 50:1593-1601.

Coggins, P., D. E. Rowe, J. C. Wilson, and S. Kumari. 2010. Storage and temperature effects on appearance and textural characteristics of conventional milk yoghurt. J. Sens. Stud. 25:549-576.

Cui, B., Y. M. Lu, C. P. Tan, G. Q. Wang, and G. H. Li. 2014. Effect of cross-linked acetylated starch content on the structure and stability of set yoghurt. Food Hydrocoll. 35:576-582.

Delikanli, B., and T. Ozcan. 2014. Effects of various whey proteins on the physicochemical and textural properties of set type nonfat yoghurt. Int. J. Dairy Technol. 67:495-503.

Espirito-Santo, A. P., A. Lagazzo, A. L. O. P. Sousa, P. Perego, A. Converti, and M. N. Oliveira. 2013. Rheology, spontaneous whey separation, microstructure and sensorial characteristics of probiotic yoghurts enriched with passion fruit fiber. Food Res. Int. 50:224-231.

Fangary, Y. S., M. Barigou, and J. P. K. Seville. 1999. Simulation of yoghurt flow and prediction of its end-of-process properties using rheological measurements. Food Bioprod. Process. 77:33-39.

Farah, A. 2012. Coffee: Emerging health effects and disease prevention. Pages 21-58 in Coffee Constituents. Y. Chu, ed. John Wiley \& Sons, Hoboken, NJ.

Fischer, P., M. Pollard, P. Erni, I. Marti, and S. Padar. 2009. Rheological approaches to food systems. C. R. Phys. 10:740-750.

Gabriele, D., B. de Cindio, and P. D'Antona. 2001. A weak gel model for foods. Rheol. Acta 40:120-127.

Graham, H. N. 1992. Green tea composition, consumption, and polyphenol chemistry. Prev. Med. 21:334-350.

Han, X., L. Zhang, M. Du, H. Yi, J. Li, and L. Zhang. 2012. Effects of copper on the post acidification of fermented milk by St. thermophilus. J. Food Sci. 77:M25-M28.

Hasni, I., P. Bourassa, S. Hamdani, G. Samson, R. Carpentier, and H. A. Tajmir-Riahi. 2011. Interaction of milk $\alpha$ - and $\beta$-caseins with tea polyphenols. Food Chem. 126:630-639.

Jakobek, L. 2015. Interactions of polyphenols with carbohydrates, lipids and proteins. Food Chem. 175:556-567.
Jaros, D., H. Rohm, A. Haque, C. Bonaparte, and W. Kneifel. 2002. Influence of the starter culture on the relationship between dry matter content and physical properties of set-style yogurt. Milchwissenschaft-Milk Sci. Int. 57:325-328

Jobstl, E., J. O'Connell, J. P. A. Fairclough, and M. P. Williamson. 2004. Molecular model for astringency produced by polyphenol/ protein interactions. Biomacromolecules 5:942-949.

Lin, H. C., P. C. Chen, T. J. Cheng, and R. L. C. Chen. 2004. Formation of tannin-albumin nano-particles at neutral $\mathrm{pH}$ as measured by light scattering techniques. Anal. Biochem. 325:117-120.

Loveday, S. M., A. Sarkar, and H. Singh. 2013. Innovative yoghurts: Novel processing technologies for improving acid milk gel texture. Trends Food Sci. Technol. 33:5-20.

Lucey, J. A. 2002. Formation and physical properties of milk protein gels. J. Dairy Sci. 85:281-294.

Lucey, J. A. 2004. Cultured dairy products: An overview of their gelation and texture properties. Int. J. Dairy Technol. 57:77-84.

McCann, T. H., F. Fabre, and L. Day. 2011. Microstructure, rheology and storage stability of low-fat yoghurt structured by carrot cell wall particles. Food Res. Int. 44:884-892.

Mokrzycki, W. S., and M. Tatol. 2011. Color difference $\Delta \mathrm{E}-\mathrm{A}$ survey. Mach. Graph. Vision 20:383-411.

Mullineux, G., and M. J. H. Simmons. 2008. Influence of rheological model on the processing of yoghurt. J. Food Eng. 84:250-257.

Nguyen, H. T. H., L. Ong, S. E. Kentish, and S. L. Gras. 2015. Homogenisation improves the microstructure, syneresis and rheological properties of buffalo yoghurt. Int. Dairy J. 46:78-87.

Poncet-Legrand, C., A. Edelmann, J. L. Putaux, D. Cartalade, P. Sarni-Manchado, and A. Vernhet. 2006. Poly(L-proline) interactions with flavan-3-ols units: Influence of the molecular structure and the polyphenol/protein ratio. Food Hydrocoll. 20:687-697.

Purwandari, U., N. P. Shah, and T. Vasiljevic. 2007. Effects of exopolysaccharide-producing strains of Streptococcus thermophilus on technological and rheological properties of set-type yoghurt. Int. Dairy J. 17:1344-1352.

Puvanenthiran, A., C. Stevovitch-Rykner, T. H. McCann, and L. Day. 2014. Synergistic effect of milk solids and carrot cell wall particles on the rheology and texture of yoghurt gels. Food Res. Int. 62:701-708.

Richard, T., D. Lefeuvre, A. Descendit, S. Quideau, and J. P. Monti. 2006. Recognition characters in peptide-polyphenol complex formation. Biochim. Biophys. Acta 1760:951-958.

Riener, J., F. Noci, D. A. Cronin, D. J. Morgan, and J. G. Lyng. 2010. A comparison of selected quality characteristics of yoghurts prepared from thermosonicated and conventionally heated milks. Food Chem. 119:1108-1113.

Sengul, M., T. Erkaya, M. Sengul, and H. Yildiz. 2012. The effect of adding sour cherry pulp into yoghurt on the physicochemical properties, phenolic content and antioxidant activity during storage. Int. J. Dairy Technol. 65:429-436.

Siebert, K. J., N. V. Troukhanova, and P. Y. Lynn. 1996. Nature of polyphenol-protein interactions. J. Agric. Food Chem. 44:80-85.

von Staszewski, M., R. J. Jagus, and A. M. R. Pilosof. 2011. Influence of green tea polyphenols on the colloidal stability and gelation of WPC. Food Hydrocoll. 25:1077-1084.

Walstra, P., J. T. M. Wouters, and T. J. Geurts. 2006. Dairy Science and Technology. CRC Press, Boca Raton, FL.

Woof, J. B., and J. S. Pierce. 1968. Study of protein-polyphenol interaction by differential spectroscopy. J. Inst. Brew. 74:544-549.

Xu, Z., S. Li, G. Gong, Z. Liu, Z. Wu, and C. Ma. 2015. Influence of different acidifying strains of Lactobacillus delbrueckii ssp. bulgaricus on the quality of yoghurt. Food Sci. Technol. Res. 21:263-269.

Yilmaz, C., and V. Gokmen. 2013. Compositional characteristics of sour cherry kernel and its oil as influenced by different extraction and roasting conditions. Ind. Crops Prod. 49:130-135. 